\title{
Longitudinal association of 25-hydroxyvitamin D with adipokines and markers of glucose metabolism among Brazilian pregnant women
}

\author{
Camila Benaim ${ }^{1,2}$, Paula Guedes Cocate ${ }^{1,2}$, Erica Guimarães de Barros ${ }^{1}$, Nadya Helena Alves-Santos ${ }^{1,2}$, \\ Amanda Caroline Cunha Figueiredo ${ }^{1,2}$, Ana Beatriz Franco-Sena ${ }^{1,3}$, Jaqueline Lepsch ${ }^{1,4}$, \\ Amanda Rodrigues Amorim Adegboye ${ }^{5}$, Rana Mokhtar ${ }^{6}$, Michael F. Holick ${ }^{6}$ and Gilberto Kac ${ }^{1,2 *}$ \\ ${ }^{1}$ Nutritional Epidemiology Observatory, Department of Social and Applied Nutrition, Institute of Nutrition Josué de Castro, \\ Rio de Janeiro Federal University, Rio de Janeiro 21941-590, RJ, Brazil \\ ${ }^{2}$ Postgraduate Program in Nutrition, Institute of Nutrition Josué de Castro, Rio de Janeiro Federal University, Rio de Janeiro \\ 21941-590, RJ, Brazil \\ ${ }^{3}$ Department of Social Nutrition, Emília de Jesus Ferreiro Nutrition School, Fluminense Federal University, Niteroi \\ 24020-140, Brazil \\ ${ }^{4}$ Faculty of Nutrition, Santa Ursula University, Rio de Janeiro 22231-040, RJ, Brazil \\ ${ }^{5}$ Department of Psychology, Social Work and Counselling, Faculty of Education and Health, University of Greenwich, London \\ SE9 2UG, UK \\ ${ }^{6}$ Section of Endocrinology, Diabetes and Nutrition, Department of Medicine, Boston University School of Medicine (BUSM), \\ Boston, MA 02118, USA
}

(Submitted 26 December 2017 - Final revision received 24 August 2018 - Accepted 27 September 2018)

\begin{abstract}
This study aimed to evaluate the longitudinal association of vitamin D status with glycaemia, insulin, homoeostatic model assessment of insulin resistance, adiponectin and leptin. A prospective cohort with 181 healthy, pregnant Brazilian women was followed at the 5th-13th, 20th-26th and 30th-36th gestational weeks. In this cohort, 25-hydroxyvitamin D (25(OH)D) plasma concentrations were analysed using liquid chromatography-tandem MS. Vitamin D status was categorised as sufficient or insufficient using the Endocrine Society Practice Guidelines $(\geq 75 /<75 \mathrm{nmol} / \mathrm{l})$ and the Institute of Medicine $(\geq 50 /<50 \mathrm{nmol} / \mathrm{l})$ thresholds. Linear mixed-effect regression models were employed to evaluate the association between vitamin $\mathrm{D}$ status and each outcome, considering interaction terms between vitamin $\mathrm{D}$ status and gestational age $(P<0 \cdot 1)$. At baseline, $70.7 \%$ of pregnant women had $25(\mathrm{OH}) \mathrm{D}$ levels $<75 \mathrm{nmol} / \mathrm{l}$ and $16 \%$ had levels $<50 \mathrm{nmol} / \mathrm{l}$. Women with sufficient vitamin D status at baseline, using both thresholds, presented lower glycaemia than those with insufficient 25(OH)D. Pregnant women with $25(\mathrm{OH}) \mathrm{D}$ concentrations $<75 \mathrm{nmol} / 1$ showed lower insulin $(\beta=-0 \cdot 12 ; 95 \% \mathrm{CI}-0 \cdot 251,0 \cdot 009 ; P=0 \cdot 069)$ and adiponectin $(\beta=-0 \cdot 070 ; 95 \% \mathrm{CI}$ $-0 \cdot 150,0 \cdot 010 ; P=0.085)$ concentrations throughout pregnancy than those with $25(\mathrm{OH}) \mathrm{D}$ levels $\geq 75 \mathrm{nmol} / \mathrm{l}$. Pregnant women with $25(\mathrm{OH}) \mathrm{D}$ $<50 \mathrm{nmol} / \mathrm{l}$ at baseline presented significantly higher leptin concentrations than those with 25(OH)D levels $\geq 50 \mathrm{nmol} / 1$ ( $\beta=-0 \cdot 253 ; 95 \% \mathrm{CI}$ $-0.044,0.550 ; P=0.095)$. The baseline status of vitamin D influences the biomarkers involved in glucose metabolism. Vitamin D-sufficient women at baseline had higher increases in insulin and adiponectin changes throughout gestation than those who were insufficient.
\end{abstract}

Key words: Adipokines: Biomarkers: Glycaemia: Pregnancy: Vitamin D

Prevention of gestational diabetes mellitus (GDM) is a key intervention to circumvent the maternal and fetal consequences of this disease. The primary method of preventing GDM is by lifestyle changes, such as physical activity and diet ${ }^{(1)}$. One important modifiable risk factor is vitamin D deficiency among pregnant women. Vitamin D deficiency is considered highly prevalent worldwide and often persists during pregnancy ${ }^{(2,3)}$.
Studies have suggested that low concentrations of vitamin D may be associated with alterations in glucose metabolism ${ }^{(4)}$, can be a risk factor for $\mathrm{GDM}^{(5-7)}$ and are characterised by glucose intolerance or glycaemia values higher than the normal range when detected during pregnancy ${ }^{(8)}$.

One possible mechanism by which vitamin $\mathrm{D}$ may act on glucose metabolism is by increasing adiponectin secretion ${ }^{(9,10)}$.

Abbreviations: $1,25(\mathrm{OH})_{2} \mathrm{D}_{3}, 1,25$-dihydroxyvitamin $\mathrm{D}_{3} ; 25(\mathrm{OH}) \mathrm{D}, 25$-hydroxyvitamin D; ESPG, Endocrine Society Practice Guidelines; GDM, gestational diabetes mellitus; HOMA-IR, homoeostatic model assessment of insulin resistance; IOM, Institute of Medicine.

*Corresponding author: G. Kac, fax +55 21 22808343, email gilberto.kac@gmail.com 
This adipokine has insulin-sensitisation properties of the target cells (liver, skeletal muscle and adipose tissue) and can enhance glucose uptake in muscle tissue ${ }^{(11-13)}$. Adiponectin also protects $\beta$-cells from immune attack and reduces insulin resistance through immunoregulatory and anti-inflammatory effects $^{(11-14)}$. In pregnant women, concentrations of adiponectin have been inversely associated with adverse maternal outcomes, such as $\mathrm{GDM}^{(15,16)}$, overweight and obesity ${ }^{(17)}$. During pregnancy, a reduction in maternal plasma adiponectin concentrations is expected ${ }^{(18,19)}$. Many factors can influence the expression of this adipokine. Vitamin D concentration is one example $^{(13,20)}$, as it down-regulates pro-inflammatory cytokines and up-regulates anti-inflammatory cytokines. Vitamin D appears to be positively associated with adiponectin gene expression and suppresses the renin-angiotensin-aldosterone system (RAAS) components secreted by adipocytes, thus contributing to increased adiponectin secretion ${ }^{(20-22)}$. Low 25-hydroxyvitamin D (25(OH)D) concentrations may then reduce the secretion of adiponectin and could be considered a risk factor for GDM and insulin resistance ${ }^{(13,23,24)}$.

Leptin is a hormone that regulates lipid metabolism and inflammation by influencing glucose metabolism in an inverse manner to adiponectin, that is, it reduces insulin sensitivity ${ }^{(25)}$. Leptin is directly associated with pre-eclampsia, GDM and macrosomia ${ }^{(26,27)}$. Studies have shown an inverse association between vitamin $\mathrm{D}$ and leptin concentrations ${ }^{(28-30)}$. The mechanism by which vitamin D metabolites impact leptin levels remains unclear. One possible mechanism is that the fat solubility of vitamin $\mathrm{D}$ can cause it to be sequestered in fat tissues, leading to a high level of intracellular $\mathrm{Ca}$ that increases lipogenesis and decreases lipolysis ${ }^{(31)}$. A lower serum vitamin D may lead to a higher serum leptin, since its concentration is related to greater body fat mass ${ }^{(32,33)}$. However, randomised clinical trials have found no association between vitamin $\mathrm{D}$ supplementation and changes in leptin concentrations ${ }^{(31,34)}$

There are few studies evaluating the association between vitamin D status, glycaemia and adipokines during pregnancy, particularly among healthy pregnant women without comorbidities such as $\operatorname{GDM}^{(31,35,36)}$. The aim of this study was to evaluate the vitamin D status of pregnant women in the first trimester and, if variation in vitamin D status during pregnancy was associated with changes in adiponectin, leptin and glycaemia concentrations throughout pregnancy among a cohort of healthy Brazilian women.

\section{Methods}

\section{Study design}

This study consists of a prospective cohort with healthy pregnant adult women from a public health care centre in Rio de Janeiro, Brazil, carried out from November 2009 to October 2011.

A total of 299 women were invited to participate in the study in accordance with the following eligibility criteria: (a) being between 5 and 13 weeks of gestation, (b) aged between 20 and 40 years and (c) without any known infectious or chronic noncommunicable diseases (except obesity). Criteria for exclusion after baseline clinical evaluation consisted of the following: miscarriage ( $n$ 25), chronic arterial hypertension ( $n$ 3), multiple gestation $(n 4)$, diagnosis of infectious or non-communicable disease after starting of the study ( $n 11$ ), advanced pregnancy ( $\geq 14$ weeks of gestation, $n 15)$, pre-natal care withdrawn $(n 7)$, stillbirth ( $n$ 5), no vitamin D measured at baseline ( $n$ 30), self-reported glycaemia alteration $(n$ 12) and no biochemical analyses performed $(n 1)$.

\section{Biochemical analyses}

Venous blood samples were taken after a 12-h overnight fasting at three different visits (first, second and third gestational trimesters). Samples were immediately centrifuged $(5000 \mathrm{rpm}$ for $5 \mathrm{~min}$ ), aliquoted and stored at $-80^{\circ} \mathrm{C}$ until further analysis. Plasma samples were used to determine 25(OH)D (nmol/l), leptin (ng/l) and adiponectin ( $\mathrm{ng} / \mathrm{ml})$ concentrations.

\section{Main independent variable}

Plasma 25(OH)D concentrations were analysed using liquid chromatography-tandem MS (LC-MS/MS) at the Quest Diagnostics Nichols Institute Laboratory (San Juan Capistrano) using the LC Thermo Cohesive System coupled to a Thermo Quantum Ultra Mass Spectrometer (Thermo Fisher). This method is the 'gold standard' with analytical measurement range of $10-640 \mathrm{nmol} / \mathrm{l}$ and the $\mathrm{CV}<10 \%$.

The $25(\mathrm{OH}) \mathrm{D}$ concentrations at baseline ( 5 th-13th gestational weeks) were used to determine vitamin D status. Pregnant women were categorised as being vitamin D sufficient or insufficient using two cut-points based on the Endocrine Society Practice Guidelines (ESPG) and the Institute of Medicine (IOM). According to the ESPG, vitamin D sufficiency and insufficiency are defined as having $25(\mathrm{OH}) \mathrm{D}$ concentrations $\geq 75$ and $<75 \mathrm{nmol} / \mathrm{l}$, respectively ${ }^{(2)}$. Using the IOM cut-points, sufficiency and insufficiency were defined as $25(\mathrm{OH}) \mathrm{D}$ concentrations $\geq 50$ or $<50 \mathrm{nmol} / 1$, respectively ${ }^{(37)}$. There are controversies in the literature as to which cut-point of vitamin D for insufficiency is the most appropriate. There is also no specific guideline set forth for pregnant women. We have decided to report both cut-points to increase transparency and to allow for comparability between various studies in the literature.

\section{Dependent variables}

Serum fasting glycaemia was estimated by enzymatic colorimetric methods using commercial kits (Linco Research and Wiener Lab., respectively), and insulin concentrations were assessed by ELISA using specific commercial kits designed for humans (Millipore), with sensitivity of $2 \mu \mathrm{U} / \mathrm{ml}$. Homoeostatic model assessment of insulin resistance (HOMA-IR) was calculated based on the product of fasting insulin $(\mu \mathrm{U} / \mathrm{ml})$ and glucose $(\mathrm{mmol} / \mathrm{l})$ divided by $22 \cdot 5^{(38)}$. Adipokines were evaluated using ELISA, with sensitivities of $0.78 \mathrm{ng} / \mathrm{ml}$ for adiponectin and $5 \mathrm{ng} / \mathrm{l}$ for leptin. 


\section{Covariate assessment}

A structured questionnaire administered at baseline was used to collect information on study population characteristics, including age (year), per-capita monthly household income (USD), parity (nulliparous or primiparous/multiparous) and selfreported skin colour (white, black or mixed). Date of first blood collection was used to define the season at baseline (summer, autumn, winter and spring).

Anthropometric measurements were collected according to standardised procedures at baseline ${ }^{(39)}$. Weight was measured using a digital scale (Filizzola PL 150; Filizzola Ltda) at each gestational trimester, and height was measured in duplicate using a portable stadiometer (Seca Ltda). The early pregnancy BMI was calculated using the following formula: weight at baseline $(\mathrm{kg}) /$ height $^{2}\left(\mathrm{~m}^{2}\right)$. The gestational age was obtained from the first ultrasonography (USG) examination $(92.3 \%$; $n$ 167) or using the reported date of the last menstrual period if the USG was not performed before the 24 th week of gestation $(7.7 \% ; n 14)$.

The total dietary vitamin D intake $(\mu \mathrm{g} / \mathrm{d})$ was calculated using Nutritional Composition Tables from the Brazilian Institute of Geography and Statistics ${ }^{(40)}$ according to a semi-quantitative $F_{F Q}{ }^{(41)}$. The FFQ was validated for the adult population of Rio de Janeiro ${ }^{(41)}$ and administered in the first trimester of gestation by trained interviewers and referring to intake of the last 6 months. Data on vitamin D supplementation were selfreported throughout pregnancy (first, second and third trimesters).

\section{Statistical analysis}

Data distribution was analysed according to the Shapiro-Wilk test. Maternal age, vitamin D intake, per-capita family income, early pregnancy BMI, glycaemia, insulin, HOMA-IR, adiponectin and leptin were not normally distributed (Shapiro-Wilk test $P$ value $<0 \cdot 05$ ). The sample characteristics are described using medians and interquartile ranges. Categorical data are presented as absolute values ( $n$ ) and relative frequencies (\%). Baseline characteristics were stratified according to vitamin D status (sufficiency $v$. insufficiency). To compare medians and frequencies, the Mann-Whitney $U$ test and the $\chi^{2}$ test were used, respectively.

Dropout analyses were performed to verify the presence of selection bias comparing those who completed the study to those who were lost to follow-up. The following variables were considered: vitamin D status according to thresholds, dietary vitamin D intake, age, early pregnancy BMI, per-capita family income, glycaemia, insulin, HOMA-IR, adiponectin and leptin concentrations, parity, self-reported skin colour and season at recruitment.

Scatter plots containing longitudinal prediction and 95\% CI were constructed to illustrate the variation in glycaemia and adipokine concentrations during pregnancy according to vitamin D baseline status.

Linear mixed-effect (LME) models were performed to assess the longitudinal associations of vitamin $\mathrm{D}$ baseline status with the outcomes throughout pregnancy. The modelling process allows the inclusion of time-dependent and time-independent variables; it is robust to deal with unbalanced time intervals and considers the correlation between repeated measures ${ }^{(42,43)}$. Interactions between vitamin D baseline status and gestational age were considered to explore the longitudinal behaviour of the evaluated outcomes. The LME models were adjusted for confounders selected by biological plausibility and statistical significance $(P<0 \cdot 2)$ in the bivariate analysis for each of the five outcomes (glycaemia, insulin, HOMA-IR, adiponectin and leptin). The test to detect interactions was low powered. We considered $P<0 \cdot 1^{(44)}$ as a threshold to define statistical significance for the interaction terms and $P<0.05$ for the main effect variables.

All analyses were performed in Stata 12.0 (Stata Corporation). The significant interactions identified in the LME models were illustrated by graphs plotted with RStudio 3.3.1 software ${ }^{(45)}$.

\section{Ethical approval}

This study was conducted according to the guidelines of the Declaration of Helsinki. The Rio de Janeiro Federal University Maternity Hospital Ethics Committee (protocol number: 0023.0.361.000-08) and the Municipal Secretary of Rio de Janeiro Ethics Committee (protocol number: 0139.0.314.000-09) approved all procedures involving humans. All participants signed an informed consent for participation in the study.

\section{Results}

The baseline sample comprised 181 pregnant women. From baseline to the second-trimester follow-up, 11 women moved out from the pre-natal program, 2 withdrew consent, 4 abandoned pre-natal care at the study site, 12 missed the follow-up interview and 1 had no biochemical analyses performed, leaving a sample of 151 women at the second trimester. From the second to the third visit, six women were classified as lost to follow-up and seven had no biochemical analyses performed. Eleven women missed the second-trimester interview but returned to the study in the third trimester. Therefore, our final sample at the third trimester comprised 149 women (online Supplementary Fig. S1).

In total, 149 women completed the study, and 32 were lost to follow-up. There were no significant differences between women who completed the study compared to those who were lost during follow-up (online Supplementary Table S1).

At baseline, women had a median age of 26 (IQR 22.0-31.0) years, early pregnancy BMI of 23.7 (IQR $21.9-27 \cdot 0) \mathrm{kg} / \mathrm{m}^{2}$, percapita family income of 292.4 (IQR 184.8-421.0) USD and reported a vitamin D intake of 3.4 (IQR 2.22-4.64) $\mu \mathrm{g} / \mathrm{d}$, and $46.9 \%$ self-reported their skin colour to be mixed. The prevalence of vitamin D insufficiency was $70.7 \%$ ( $n$ 128/181) and $16 \cdot 0 \%$ ( $n$ 29/181) according the cut-offs proposed by the ESPG and the IOM, repectively. Women who began the study in the winter, compared to those who began in summer, were more likely to be vitamin D insufficient (ESPG: 33.6 v. $15.6 \%$, respectively, $P<0.001$; IOM: $51.7 \quad v .3 .5 \%$, respectively, $P<0.001$ ) (Table 1). None of the women who participated in 
Table 1. Baseline characteristics of the study population according to vitamin D sufficiency status in the first trimester of pregnancy (Medians and interquartile ranges (IQR); numbers and percentages)

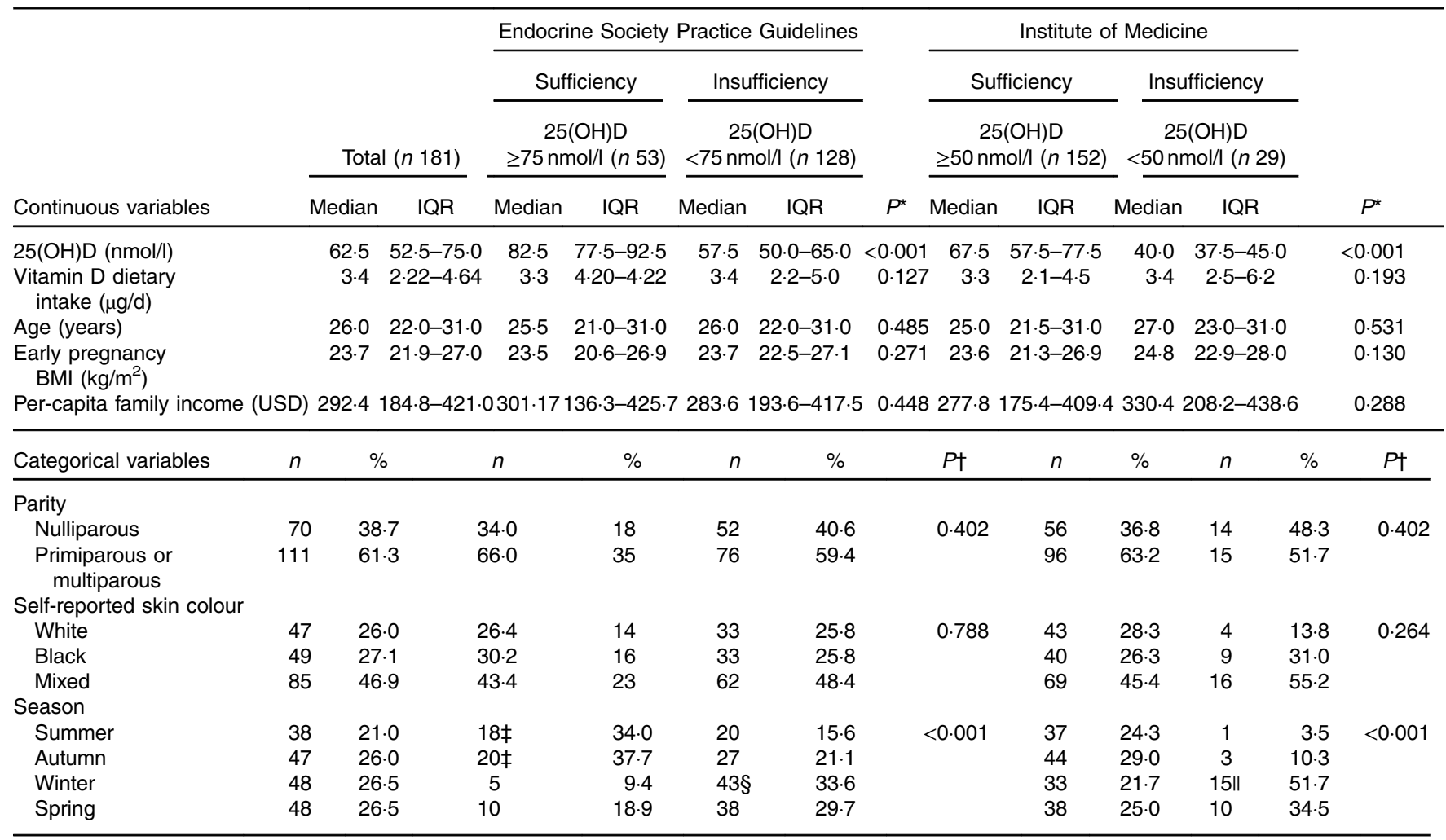

25(OH)D, 25-hydroxyvitamin D.

* $P$ value refers to the Mann-Whitney test. $P$ values $<0.05$ were considered statistically significant.

t $P$ value refers to the $x^{2}$ test. $P$ values $<0.05$ were considered statistically significant.

$\ddagger$ Among women with vitamin D sufficiency according to Endocrine Society Practice Guidelines at baseline, we observed significantly higher proportions of women entering pregnancy in the summer and in the autumn, compared with those who became pregnant in the winter.

$\S$ Among women with vitamin D insufficiency according to Endocrine Society Practice Guidelines at baseline, we observed a significantly higher proportion of women entering pregnancy in the winter than in the summer.

\| Among women with vitamin D insufficiency according to the Institute of Medicine at baseline, we observed a significantly higher proportion of women entering pregnancy in the winter than in the summer.

the study received nutritional vitamin D supplementation (data not shown).

Pregnant women with vitamin D sufficiency at baseline showed lower glycaemia when compared to insufficient women (ESPG: median 79.5 v. $84.0 \mathrm{mg} / \mathrm{l}$, respectively, $P=0.003 ;$ IOM: median $83.0 \quad v .84 .0 \mathrm{mg} / \mathrm{l}$, respectively, $P=0.034$ ) (Table 2 ). The glycaemia decreased from the first to the second trimester, followed by a slight increase from the second to the third trimester onwards, in both women with vitamin D sufficiency and insufficiency at baseline (Fig. 1(a) and (b)). However, the rate of change for glycaemia throughout pregnancy did not show a significant difference between the baseline vitamin D groups (Table 3). Similar results were observed when $25(\mathrm{OH}) \mathrm{D}$ was analysed throughout pregnancy (Fig. 2(a) and (b); Table 4).

The rate of change in insulin was greater among vitamin D sufficient women at baseline (ESPG: $\beta=0 \cdot 166 ; 95 \%$ CI 0.047, 0.285, $P=0.006$; IOM: $\beta=0.091 ; 95 \%$ CI 0.019, 0.162, $P=0.013$ ) (Fig. 1(c) and (d)). There was a less pronounced increase in insulin throughout pregnancy among vitamin D insufficient women compared to those who started with sufficient status according to ESPG (interaction $\beta=-0.12 ; 95 \% \mathrm{CI}-0.251,0 \cdot 009 ; P=0.069$ ) (Table 3). We found significant results when $25(\mathrm{OH}) \mathrm{D}$ was analysed throughout pregnancy using the IOM thresholds (interaction $\beta=-0 \cdot 153 ; 95 \%$ CI $-0.325,0.018 ; P=0.080$ ) (Fig. 2(c) and (d); Table 4).

There was a tendency for lower HOMA-IR in the group of women classified as sufficient vitamin D status at baseline when compared to those with vitamin D insufficient status (ESPG: median $0.65 v$. 0.93 , respectively, $P=0.062$; IOM: median $0.82 v$. $1 \cdot 14$, respectively, $P=0.071$ ) (Table 2). HOMA-IR increased throughout gestation among women with sufficient vitamin D status at baseline (ESPG: $\beta=0.019 ; 95 \%$ CI 0.00001, 0.039; $P=0.050)$ but did not change in the insufficient group (Fig. 1(e) and (f)). However, the results were not significant for this biomarker when baseline vitamin D-sufficient and insufficient women were compared (Table 3). We found significant results when $25(\mathrm{OH}) \mathrm{D}$ was analysed throughout pregnancy using the IOM thresholds (interaction $\beta=-0.030 ; 95 \% \mathrm{CI}$ $-0.065,0.005 ; P=0.094$ ) (Fig. 2(e) and (f); Table 4).

The trend in changes in adiponectin throughout pregnancy showed an increase from the beginning of pregnancy until the second trimester and was followed by a slight decrease at the end of gestation for both vitamin D status groups, whether measured at baseline or when $25(\mathrm{OH}) \mathrm{D}$ varied throughout 
Table 2. Markers of glucose and adipokines concentrations of the study population according to vitamin D sufficiency status in the first trimester of pregnancy (Medians and interquartile ranges (IQR))

\begin{tabular}{|c|c|c|c|c|c|c|c|c|c|c|c|c|c|c|c|c|c|}
\hline \multirow[b]{4}{*}{ Variables } & \multirow[b]{4}{*}{$n$} & & & & \multicolumn{5}{|c|}{ Endocrine Society Practice Guidelines } & \multirow[b]{4}{*}{$P^{\star}$} & \multirow[b]{4}{*}{$n$} & \multicolumn{5}{|c|}{ Institute of Medicine } & \multirow[b]{4}{*}{$P^{\star}$} \\
\hline & & & & & & ficiency & & & fficiency & & & & iciency & & Insu & fficiency & \\
\hline & & \multicolumn{2}{|c|}{ Total } & \multirow[b]{2}{*}{$n$} & \multicolumn{2}{|c|}{$25(\mathrm{OH}) \mathrm{D} \geq 75 \mathrm{nmol} / \mathrm{l}$} & \multirow[b]{2}{*}{$n$} & \multicolumn{2}{|c|}{$25(\mathrm{OH}) \mathrm{D}<75 \mathrm{nmol} / \mathrm{l}$} & & & \multicolumn{2}{|c|}{$25(\mathrm{OH}) \mathrm{D} \geq 50 \mathrm{nmol} / \mathrm{l}$} & \multirow[b]{2}{*}{$n$} & \multicolumn{2}{|c|}{$25(\mathrm{OH}) \mathrm{D}<50 \mathrm{nmol} / \mathrm{l}$} & \\
\hline & & Median & IQR & & Median & IQR & & Median & IQR & & & Median & IQR & & Median & IQR & \\
\hline \multicolumn{18}{|l|}{ Glycaemia $(\mathrm{mg} / \mathrm{dl}) \dagger$} \\
\hline First trimester & 180 & 83.0 & $78 \cdot 0-88.0$ & 54 & 79.5 & $76 \cdot 0-85 \cdot 0$ & 126 & 84.0 & $79 \cdot 0-89 \cdot 0$ & 0.003 & 151 & 83.0 & $78 \cdot 0-87.0$ & 29 & 84.0 & $79 \cdot 0-95 \cdot 0$ & 0.034 \\
\hline Second trimester & 146 & 78.0 & $72 \cdot 0-83 \cdot 0$ & 42 & 77.5 & $70 \cdot 0-82 \cdot 0$ & 104 & 78.0 & $73 \cdot 0-83 \cdot 0$ & 0.204 & 122 & 77.5 & $72 \cdot 0-82 \cdot 0$ & 24 & 78.5 & $72.0-83.5$ & 0.885 \\
\hline Third trimester & 149 & $79 \cdot 0$ & $72 \cdot 0-84 \cdot 0$ & 40 & 80.5 & $71.5-84.5$ & 109 & 78.0 & $72 \cdot 0-84 \cdot 0$ & 0.991 & 123 & $78 \cdot 0$ & $71 \cdot 0-84 \cdot 0$ & 26 & 80.5 & $75 \cdot 0-84 \cdot 0$ & 0.346 \\
\hline \multicolumn{18}{|l|}{ Insulin $(\mu \mathrm{U} / \mathrm{ml})$} \\
\hline First trimester & 180 & 4.34 & $2.97-6.46$ & 53 & 3.37 & $2.64-6.01$ & 127 & 4.58 & $3.31-6.49$ & 0.125 & 152 & 4.04 & $2 \cdot 90-6 \cdot 31$ & 28 & 4.89 & $3 \cdot 28-7 \cdot 71$ & 0.141 \\
\hline Second trimester & 149 & 4.93 & $3 \cdot 21-7 \cdot 70$ & 44 & 5.07 & $3.26-7.53$ & 106 & 4.92 & $3 \cdot 19-7 \cdot 70$ & 0.921 & 125 & 4.90 & $3 \cdot 15-7 \cdot 40$ & 24 & 6.94 & $3.96-11.39$ & 0.082 \\
\hline Third trimester & 147 & 5.75 & $3.90-8.75$ & 40 & 6.89 & $4.46-11.88$ & 108 & 5.49 & $3.71-8.26$ & 0.093 & 123 & 5.65 & $4.08-8 \cdot 28$ & 24 & 7.63 & $3.69-11.70$ & 0.484 \\
\hline \multicolumn{18}{|l|}{ HOMA-IR } \\
\hline First trimester & 180 & 0.86 & $0.57-1.36$ & 54 & 0.65 & $0.50-1.23$ & 126 & 0.93 & $0.65-1.41$ & 0.062 & 152 & 0.82 & $0.56-1.30$ & 28 & $1 \cdot 14$ & $0.80-1.73$ & 0.071 \\
\hline Second trimester & 144 & 0.95 & $0.60-1.53$ & 42 & 0.94 & $0.59-1.41$ & 102 & 0.96 & $0.60-1.55$ & 0.812 & 120 & 0.95 & $0.59-1.39$ & 24 & $1 \cdot 16$ & $0.70-2.18$ & 0.106 \\
\hline Third trimester & 144 & 1.12 & $0.74-1.69$ & 38 & 1.38 & $0.78-1.94$ & 106 & 1.08 & $0.70-1.65$ & 0.176 & 120 & $1 \cdot 10$ & $0.74-1.57$ & 24 & 1.60 & $0.72-2.72$ & 0.352 \\
\hline \multicolumn{18}{|l|}{ Adiponectin $(\mu \mathrm{g} / \mathrm{ml})$} \\
\hline First trimester & 181 & 4.96 & $3.57-7.19$ & 53 & 4.49 & $3 \cdot 12-6.55$ & 128 & $5 \cdot 26$ & $3.61-7.28$ & 0.170 & 152 & 4.95 & $3.52-7.08$ & 29 & 5.68 & $4.07-7.91$ & 0.254 \\
\hline Second trimester & 146 & 5.05 & $3.52-8.46$ & 42 & 5.06 & $3.65-10.91$ & 104 & 5.04 & $3.36-7.80$ & 0.469 & 123 & 4.75 & $3.65-10.91$ & 23 & $6 \cdot 21$ & $3 \cdot 92-12 \cdot 17$ & 0.123 \\
\hline Third trimester & 148 & 4.59 & $3.42-6.97$ & 41 & 4.69 & $3.43-7.32$ & 107 & 4.45 & $3.32-6.91$ & 0.750 & 123 & 4.45 & $3.32-6.63$ & 125 & $5 \cdot 21$ & $3 \cdot 67-7.22$ & 0.494 \\
\hline \multicolumn{18}{|l|}{ Leptin (ng/l) } \\
\hline First trimester & 181 & $166 \cdot 7$ & $99 \cdot 9-262 \cdot 1$ & 54 & 134.5 & $83 \cdot 3-241 \cdot 7$ & 127 & 174.2 & $108 \cdot 3-280 \cdot 5$ & 0.093 & 152 & 161.0 & $97 \cdot 7-268 \cdot 3$ & 29 & 174.2 & $116 \cdot 6-246 \cdot 9$ & 0.588 \\
\hline Second trimester & 151 & 247.8 & $165 \cdot 7-418 \cdot 0$ & 44 & $209 \cdot 3$ & $158 \cdot 9-354 \cdot 2$ & 107 & 268.0 & $172 \cdot 6-431 \cdot 8$ & 0.196 & 126 & 234.0 & $162 \cdot 5-418 \cdot 0$ & 25 & 327.5 & $193 \cdot 3-400 \cdot 1$ & 0.228 \\
\hline Third trimester & 149 & 249.5 & $159 \cdot 3-387 \cdot 6$ & 40 & 241.2 & $144 \cdot 2-383 \cdot 2$ & 109 & 256.6 & $159 \cdot 8-388 \cdot 7$ & 0.472 & 124 & 235.6 & $149.4-381 \cdot 2$ & 25 & 333.3 & $256 \cdot 6-472 \cdot 9$ & 0.021 \\
\hline
\end{tabular}

25(OH)D, 25-hydroxyvitamin D; HOMA-IR, homoeostatic model assessment of insulin resistance.

* $P$ value refers to the Mann-Whitney test. $P$ values $<0.05$ were considered statistically significant.

$\dagger$ To convert glucose in $\mathrm{mg} / \mathrm{dl}$ to $\mathrm{mmol} / \mathrm{l}$, multiply by 0.0555 . 
(a)

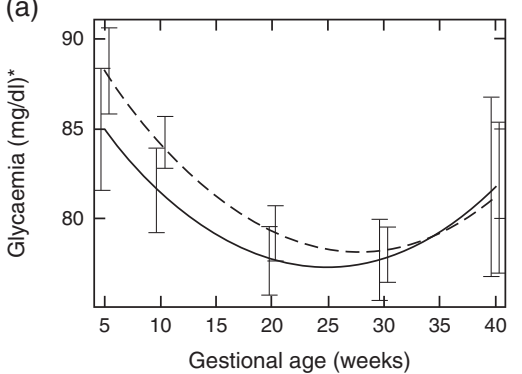

(c)

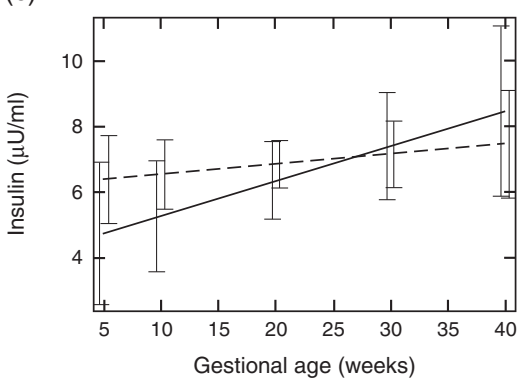

(e)

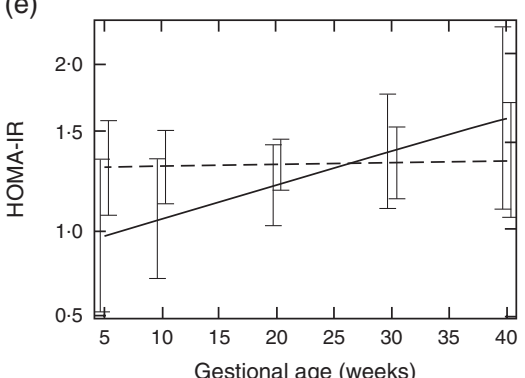

(g)

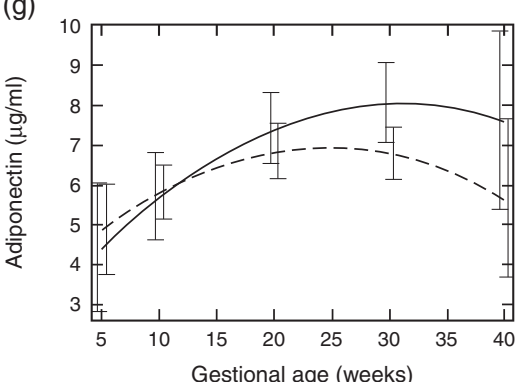

(i)

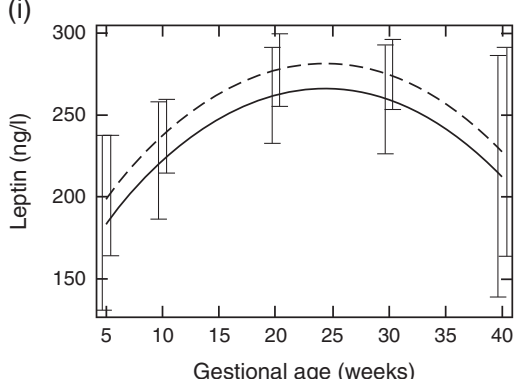

(b)

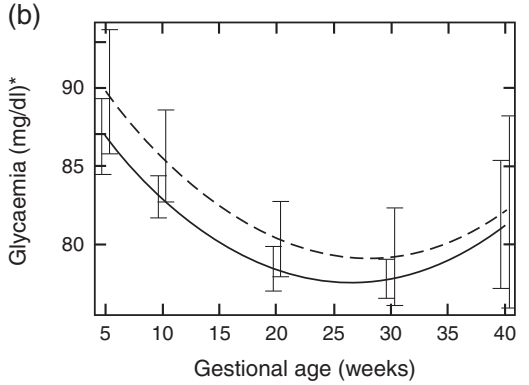

(d)

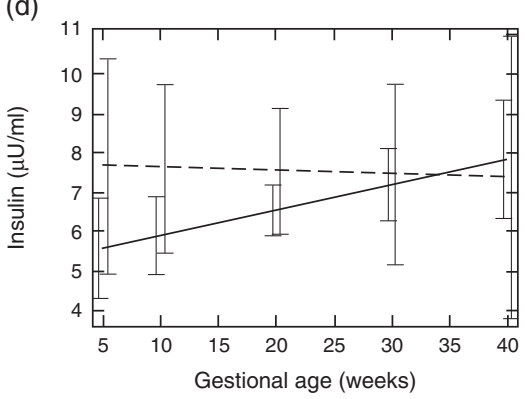

(f)

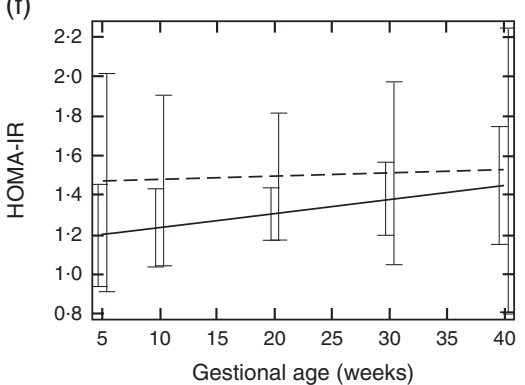

(h)

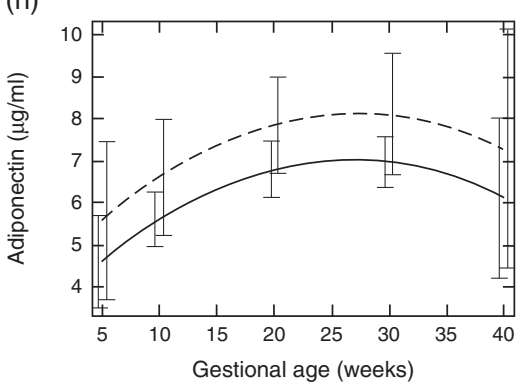

(j)

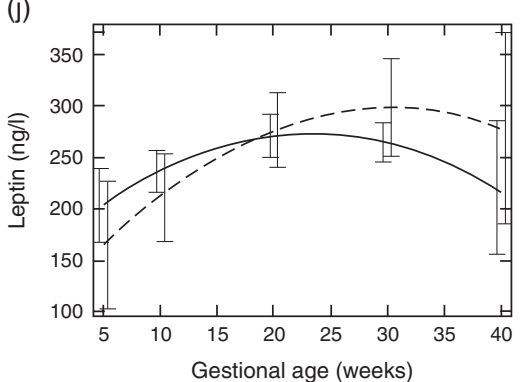

Fig. 1. Changes in glucose metabolism markers and adipokines throughout pregnancy according to vitamin D baseline status, Rio de Janeiro/Brazil, 2009-2012. Glycaemia according to vitamin D status (a) Endocrine Society Practice Guidelines and (b) the Institute of Medicine cut-off points. Insulin according to vitamin D status (c) Endocrine Society Practice Guidelines and (d) the Institute of Medicine cut-off points. Homoeostatic model assessment of insulin resistance (HOMA-IR) according to vitamin D status (e) Endocrine Society Practice Guidelines and (f) the Institute of Medicine cut-off points. Adiponectin according to vitamin D status (g) Endocrine Society Practice Guidelines and (h) the Institute of Medicine cut-off points. Leptin according to vitamin D status (i) Endocrine Society Practice Guidelines and (j) the Institute of Medicine cut-off points. ——, Sufficiency vitamin D status at baseline; - - - , insufficiency vitamin D status at baseline. * To convert glucose in $\mathrm{mg} / \mathrm{dl}$ to $\mathrm{mmol} / \mathrm{l}, \mathrm{multiply}$ by 0.0555 . 
Table 3. Markers of glucose metabolism and adipokines changes during pregnancy according to vitamin $\mathrm{D}$ adequacy status at the first trimester, Rio de Janeiro, Brazil, 2009-2011

( $\beta$-Coefficients and $95 \%$ confidence intervals)

\begin{tabular}{|c|c|c|c|c|c|c|}
\hline \multirow[b]{2}{*}{ Fixed-effectł } & \multicolumn{3}{|c|}{ Endocrine Society Practice Guidelines* } & \multicolumn{3}{|c|}{ Institute of Medicine† } \\
\hline & $\beta \S$ & $95 \% \mathrm{Cl}$ & $P \|$ & $\beta \S$ & $95 \% \mathrm{Cl}$ & $P \|$ \\
\hline \multicolumn{7}{|l|}{ Glycaemia $(\mathrm{mg} / \mathrm{dl}) \boldsymbol{\Phi}$} \\
\hline Gestational age & -0.937 & $-1.347,-0.526$ & $<0.001$ & -1.013 & $-1.405,-0.620$ & $<0.001$ \\
\hline Quadratic gestational age & 0.019 & $0.009,0.028$ & $<0.001$ & 0.019 & $0.009,0.028$ & $<0.001$ \\
\hline Vitamin D sufficiency status ${ }^{\star *}$ & 3.770 & $-0.128,7.667$ & 0.058 & 3.189 & $-1.473,7.851$ & 0.180 \\
\hline \multicolumn{7}{|l|}{ Interaction terms } \\
\hline $\begin{array}{l}\text { Gestational age } \times \text { vitamin D status }{ }^{* *} \\
\text { Insulin }(\mu \mathrm{U} / \mathrm{ml})\end{array}$ & -0.109 & $-0.273,0.055$ & $0 \cdot 192$ & -0.052 & $-0.245,0.140$ & 0.593 \\
\hline Gestational age & 0.167 & $0.048,0.287$ & 0.006 & 0.085 & $0.017,0.153$ & 0.014 \\
\hline Vitamin D sufficiency status ${ }^{\star *}$ & 2.357 & $-0.344,5.058$ & 0.087 & 1.309 & $-1.886,4.503$ & 0.422 \\
\hline $\begin{array}{l}\text { Gestational age } \times \text { vitamin D status } \\
\text { HOMA-IR }\end{array}$ & -0.121 & $-0.251,0.009$ & $0.069+\dagger$ & -0.024 & $-0.180,0.132$ & 0.762 \\
\hline Gestational age & 0.018 & $-0.005,0.041$ & $0 \cdot 116$ & 0.007 & $-0.007,0.020$ & 0.320 \\
\hline Vitamin D sufficiency status ${ }^{\star *}$ & 0.458 & $-0.053,0.970$ & 0.079 & 0.241 & $-0.366,0.848$ & 0.437 \\
\hline Gestational age $\times$ vitamin D status ${ }^{\star \star}$ & -0.016 & $-0.042,0.010$ & 0.232 & 0.0002 & $-0.031,0.031$ & 0.992 \\
\hline \multicolumn{7}{|l|}{ Adiponectin $(\mu \mathrm{g} / \mathrm{ml})$} \\
\hline Gestational age & 0.303 & $0.194,0.478$ & $<0.001$ & 0.281 & $0.148,0.415$ & $<0.001$ \\
\hline Quadratic gestational age & -0.006 & $-0.009,-0.002$ & 0.001 & -0.005 & $-0.009,-0.002$ & 0.001 \\
\hline Vitamin D sufficiency status ${ }^{\star \star}$ & 0.737 & $-0.565,2.038$ & 0.267 & 0.991 & $-0.536,2.520$ & 0.203 \\
\hline \multicolumn{7}{|l|}{ Interaction terms } \\
\hline Gestational age $\times$ vitamin $D$ status ${ }^{\star *}$ & -0.070 & $-0.150,0.010$ & $0.085+\dagger$ & 0.008 & $-0.065,0.081$ & 0.822 \\
\hline \multicolumn{7}{|l|}{ Leptin (ng/l) } \\
\hline Gestational age & $10 \cdot 122$ & $4.303,15.942$ & 0.001 & 9.517 & $4.056,14.977$ & 0.001 \\
\hline Quadratic gestational age & -0.207 & $-0.340,-0.074$ & 0.002 & -0.200 & $-0.332,-0.067$ & 0.003 \\
\hline Vitamin D sufficiency status ${ }^{\star *}$ & $12 \cdot 071$ & $-35.799,59.942$ & 0.621 & $-48 \cdot 741$ & $-104 \cdot 599,7 \cdot 117$ & 0.087 \\
\hline \multicolumn{7}{|l|}{ Interaction terms } \\
\hline Gestational age $\times$ vitamin $D$ status** & 0.214 & $-2 \cdot 323,2 \cdot 752$ & 0.869 & 2.532 & $-0.436,5.501$ & $0.094 \dagger \dagger$ \\
\hline
\end{tabular}

HOMA-IR, homoeostatic model assessment of insulin resistance.

* Sufficiency (reference category, $25(\mathrm{OH}) \mathrm{D} \geq 75 \mathrm{nmol} / \mathrm{l}) /$ inadequacy status $(25(\mathrm{OH}) \mathrm{D}<75 \mathrm{nmol} / \mathrm{l})$.

† Sufficiency (reference category, $25(\mathrm{OH}) \mathrm{D} \geq 50 \mathrm{nmol} / \mathrm{l}) /$ insufficiency status $(25(\mathrm{OH}) \mathrm{D}<50 \mathrm{nmol} / \mathrm{l})$.

¥ The adiponectin, leptin and glycaemia models were adjusted for gestational age and quadratic gestational age in weeks and for women's age, BMI and seasons (spring/summer/ autumn/winter); the insulin and HOMA-IR models were adjusted for gestational age in weeks and for women's age, BMI and seasons (spring/summer/autumn/winter). Glycaemia model: number of observations $=474$; number of groups $=182$; average of 2.6 observations per group. Insulin model: number of observations =475; number of groups = 180; average of 2.6 observations per group. HOMA-IR model: number of observations $=467$; number of groups $=182$; average of 2.6 observations per group. Adiponectin model: number of observations $=474$; number of groups $=182$; average of 2.6 observations per group. Leptin model: number of observations $=480$; number of groups $=181$; average of $2 \cdot 7$ observations per group.

$\S \beta=$ longitudinal linear regression coefficient

I To convert glucose in $\mathrm{mg} / \mathrm{dl}$ to $\mathrm{mmol} / \mathrm{l}$, multiply by 0.0555 .

$\| P$ value refers to maximum likelihood estimator.

$\star \star$ The reference category was adequate status of $25(\mathrm{OH}) \mathrm{D}$

†† $P$ values $<0.1$ were considered statistically significant.

pregnancy (Figs. 1(g) and (h) and 2(g) and (h)). Women with vitamin D insufficient status at baseline started gestation with higher median plasma levels of adiponectin, although this association was not significant $(5.26 v .4 .49 \mu \mathrm{g} / \mathrm{ml}, \quad P=0.170)$ (Table 2). However, the rate of change of adiponectin throughout pregnancy was significantly higher in women with sufficient vitamin D levels at baseline (ESPG: $\beta=-0.070$; 95\% CI -0.150 , $0.010 ; P=0.085$ ) (Table 3). Women with sufficient vitamin D status at baseline, according to IOM classification, tended to have a lower rate of change in adiponectin throughout pregnancy, although this did not reach significance (Table 3; Fig. 1(h)). The rate of change in adiponectin throughout pregnancy was significantly higher in women with sufficient vitamin D levels when this marker varied throughout pregnancy (ESPG: $\beta=-0 \cdot 056 ; 95 \%$ CI $-0 \cdot 116,0 \cdot 004 ; P=0 \cdot 066$ ) (Table 4).

There were no significant differences in leptin concentrations, comparing each trimester individually, according to ESPG, but it was found that women with inadequate vitamin D status according to IOM presented higher leptin concentrations (Table 2). Women with insufficient vitamin D status according to ESPG had a significant decrease in leptin concentrations $(\beta=-0 \cdot 259 ; 95 \% \mathrm{CI}$ $-0.424,-0.094 ; P=0.002)$. Using the IOM cut-points, the decrease was significant only within the sufficient group $(\beta=-0.214 ; 95 \%$ CI $-0.360,-0.068 ; P=0.004)$ (Fig. 1(i) and (j)). Women with insufficient vitamin $\mathrm{D}$ levels presented a greater increase in leptin concentrations, in relation to the sufficient group, according to $\operatorname{IOM}(\beta=2.532 ; 95 \%$ CI $-0.436,5.501$; $P=0.094$ ) (Table 3). These results did not hold when 25(OH)D varied throughout pregnancy (Fig. 2(i) and (j); Table 4).

\section{Discussion}

The main result of this study is the difference in the variation of adiponectin and insulin concentrations throughout pregnancy 
(a)

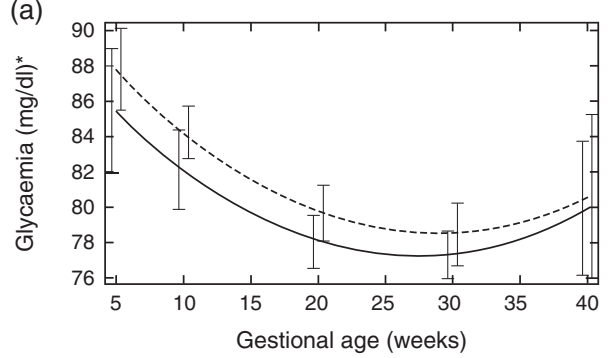

(c)

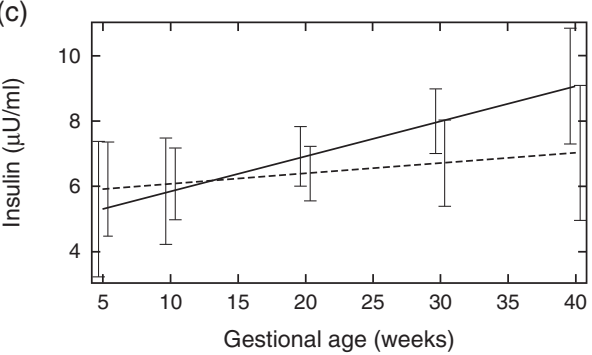

(e)

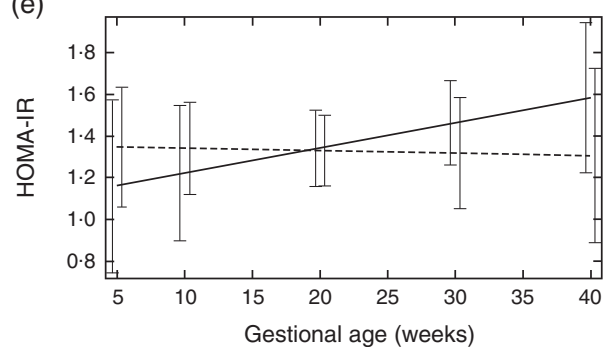

(g)

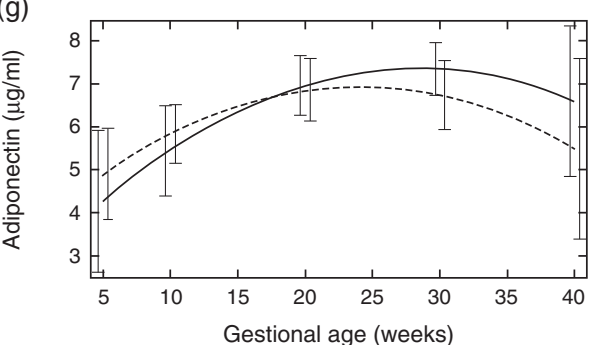

(i)

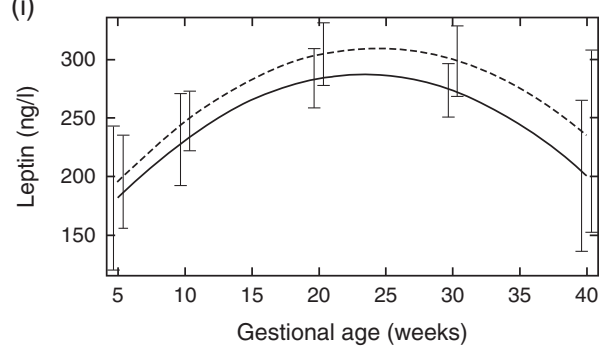

(b)

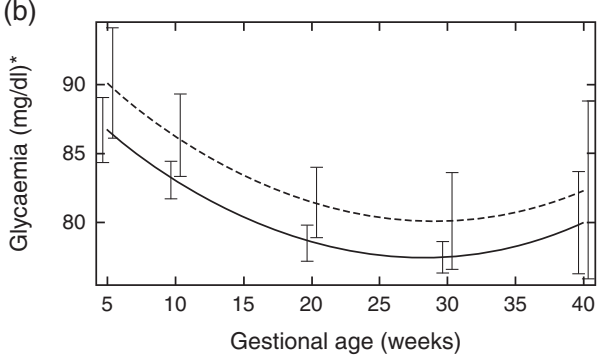

(d)

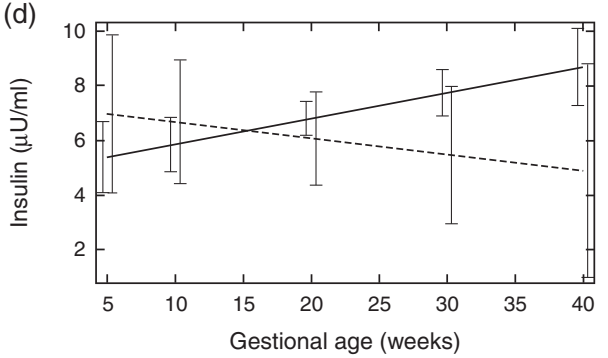

(f)

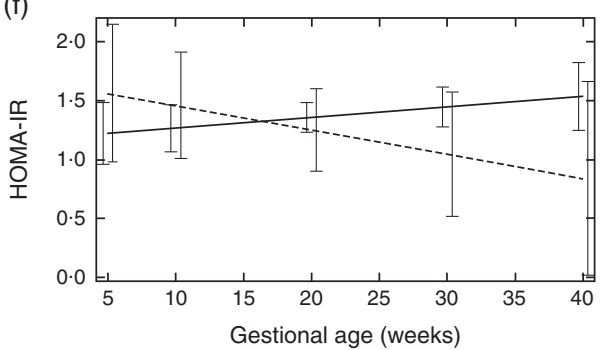

(h)

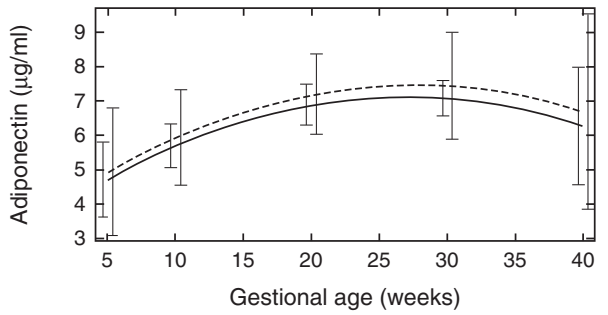

(j)

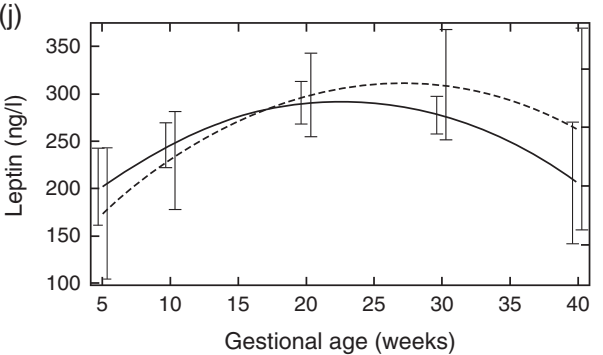

Fig. 2. Changes in glucose metabolism markers and adipokines according to vitamin D status throughout pregnancy, Rio de Janeiro/Brazil, 2009-2012. Glycaemia according to vitamin D status (a) Endocrine Society Practice Guidelines and (b) the Institute of Medicine cut-off points. Insulin according to vitamin D status (c) Endocrine Society Practice Guidelines and (d) the Institute of Medicine cut-off points. Homoeostatic model assessment of insulin resistance (HOMA-IR) according to vitamin D status (e) Endocrine Society Practice Guidelines and (f) the Institute of Medicine cut-off points. Adiponectin according to vitamin D status (g) Endocrine Society Practice Guidelines and (h) the Institute of Medicine cut-off points. Leptin according to vitamin D status (i) Endocrine Society Practice Guidelines and (j) the Institute of Medicine cut-off points. $\ldots$, Sufficiency vitamin D status during pregnancy; ----, insufficiency vitamin D status during pregnancy. ${ }^{*}$ To convert glucose in mg/dl to mmol/l, multiply by 0.0555 .

according to vitamin D baseline status defined by the ESPG. We observed that throughout pregnancy the rate of increase for both biomarkers was greater among women with vitamin $\mathrm{D}$ sufficiency compared to women who started their pregnancy in a vitamin D-deficient state. Another important finding is that women with insufficient vitamin $\mathrm{D}$ at baseline had a higher 
Table 4. Markers of glucose metabolism and adipokines according to vitamin D sufficiency status changes during pregnancy, Rio de Janeiro, Brazil, 2009-2011

( $\beta$-Coefficients and $95 \%$ confidence intervals)

\begin{tabular}{|c|c|c|c|c|c|c|}
\hline \multirow[b]{2}{*}{ Fixed-effect } & \multicolumn{3}{|c|}{ Endocrine Society Practice Guidelines* } & \multicolumn{3}{|c|}{ Institute of Medicine† } \\
\hline & $\beta \S$ & $95 \% \mathrm{Cl}$ & $P \|$ & $\beta \S$ & $95 \% \mathrm{Cl}$ & $P \|$ \\
\hline \multicolumn{7}{|l|}{ Glycaemia $(\mathrm{mg} / \mathrm{dl}) \boldsymbol{\Phi}$} \\
\hline Gestational age & -0.915 & $-1.345,-0.484$ & $<0.001$ & -0.989 & $-1.369,-0.609$ & $<0.001$ \\
\hline Quadratic gestational age & 0.017 & $0.007,0.026$ & 0.001 & 0.018 & $0.009,0.027$ & $<0.001$ \\
\hline $\begin{array}{l}\text { Vitamin D sufficiency status }{ }^{\star *} \\
\text { Interaction terms }\end{array}$ & $2 \cdot 624$ & $-1 \cdot 244,6 \cdot 492$ & 0.184 & 3.516 & $-1 \cdot 317,8 \cdot 350$ & 0.154 \\
\hline $\begin{array}{l}\text { Gestational age } \times \text { vitamin D status }{ }^{\star *} \\
\text { Insulin }(\mu \mathrm{U} / \mathrm{ml})\end{array}$ & -0.049 & $-0.215,0.116$ & 0.560 & -0.029 & $-0.260,0.202$ & 0.805 \\
\hline \multicolumn{7}{|l|}{ Insulin $(\mu \mathrm{U} / \mathrm{ml})$} \\
\hline $\begin{array}{l}\text { Gestational age } \\
\text { Vitamin D sufficiency status }{ }^{\star *}\end{array}$ & 0.988 & $-1.677,3.654$ & $\begin{array}{l}0.024 \\
0.468\end{array}$ & $\begin{array}{l}0.095 \\
2.344\end{array}$ & $\begin{array}{r}0.029,0 \cdot 160 \\
-1 \cdot 073,5 \cdot 760\end{array}$ & $\begin{array}{l}0.004 \\
0.179\end{array}$ \\
\hline $\begin{array}{l}\text { Gestational age } \times \text { vitamin D status } \\
\text { HOMA-IR }\end{array}$ & -0.076 & $-0 \cdot 199,0.047$ & 0.226 & $-0 \cdot 153$ & $-0.325,0.018$ & $0.080 \dagger \dagger$ \\
\hline Gestational age & 0.013 & $-0.006,0.031$ & 0.178 & 0.009 & $-0.004,0.022$ & 0.178 \\
\hline $\begin{array}{l}\text { Vitamin D sufficiency status }{ }^{\star *} \\
\text { Interaction terms }\end{array}$ & 0.269 & $-0.260,0.797$ & 0.319 & 0.499 & $-0.181,1 \cdot 178$ & $0 \cdot 150$ \\
\hline $\begin{array}{l}\text { Gestational age } \times \text { vitamin D status } \\
\text { Adiponectin }(\mu \mathrm{g} / \mathrm{ml})\end{array}$ & -0.014 & \multicolumn{5}{|c|}{ Adiponectin $(\mu \mathrm{g} / \mathrm{ml})$} \\
\hline Gestational age & 0.291 & $0.145,0.436$ & $<0.001$ & 0.270 & $0.148,0.392$ & $<0.001$ \\
\hline Quadratic gestational age & -0.005 & $-0.008,-0.002$ & 0.003 & -0.005 & $-0.008,-0.002$ & 0.001 \\
\hline $\begin{array}{l}\text { Vitamin D sufficiency status }{ }^{\star *} \\
\text { Interaction terms }\end{array}$ & 0.847 & $-0 \cdot 351,2 \cdot 045$ & $0 \cdot 166$ & $0 \cdot 186$ & $-1 \cdot 265,1 \cdot 637$ & 0.801 \\
\hline Gestational age $\times$ vitamin D status ${ }^{\star \star}$ & -0.056 & $-0.116,0.004$ & $0.066+\dagger$ & 0.006 & $-0.068,0.080$ & 0.878 \\
\hline \multicolumn{7}{|l|}{ Leptin (ng/l) } \\
\hline Gestational age & 14.590 & $8 \cdot 290,20 \cdot 889$ & $<0.001$ & 13.794 & $8 \cdot 143,19.445$ & $<0.001$ \\
\hline Quadratic gestational age & -0.312 & $-0.453,-0.171$ & $<0.001$ & -0.303 & $-0.440,-0.167$ & $<0.001$ \\
\hline Vitamin D sufficiency status ${ }^{* *}$ & $11 \cdot 311$ & $-41 \cdot 138,63 \cdot 760$ & 0.673 & $-40 \cdot 453$ & $-105 \cdot 123,24 \cdot 216$ & 0.220 \\
\hline \multicolumn{7}{|l|}{ Interaction terms } \\
\hline Gestational age $\times$ vitamin D status ${ }^{* \star}$ & 0.461 & $-2.053,2.975$ & 0.719 & 2.576 & $-0.888,6.041$ & 0.145 \\
\hline
\end{tabular}

HOMA-IR, homoeostatic model assessment of insulin resistance; $25(\mathrm{OH}) \mathrm{D}, 25$-hydroxyvitamin $\mathrm{D}$.

* Sufficiency (reference category, $25(\mathrm{OH}) \mathrm{D} \geq 75 \mathrm{nmol} / \mathrm{l}) / \mathrm{insufficiency} \mathrm{status}(25(\mathrm{OH}) \mathrm{D}<75 \mathrm{nmol} / \mathrm{l})$.

† Sufficiency (reference category, $25(\mathrm{OH}) \mathrm{D} \geq 50 \mathrm{nmol} / \mathrm{l}) / \mathrm{insufficiency}$ status $(25(\mathrm{OH}) \mathrm{D}<50 \mathrm{nmol} / \mathrm{l})$.

‡ The adiponectin, leptin and glycaemia models were adjusted for gestational age and quadratic gestational age in weeks and for women's age, BMI and seasons (spring/summer/ autumn/winter); the insulin and HOMA-IR models were adjusted for gestational age in weeks and for women's age, BMI and seasons (spring/summer/autumn/winter). Glycaemia model: number of observations =503; number of groups =207; average of 2.4 observations per group. Insulin model: number of observations =509; number of groups =205; average of 2.5 observations per group. HOMA-IR model: number of observations $=498$; number of groups $=207$; average of 2.4 observations per group. Adiponectin model: number of observations $=506$; number of groups $=207$; average of 2.4 observations per group. Leptin model: number of observations $=512$; number of groups $=206$; average of 2.5 observations per group.

$\S \beta=$ longitudinal linear regression coefficient.

II To convert glucose in $\mathrm{mg} / \mathrm{dl}$ to $\mathrm{mmol} / \mathrm{l}$, multiply by 0.0555 .

$\| P$ value refers to maximum likelihood estimator.

$\star \star$ The reference category was adequate status of $25(\mathrm{OH}) \mathrm{D}$

†† $P$ values $<0.1$ were considered statistically significant.

increase in leptin levels during gestation compared to the sufficient group according to the IOM classification. In addition, women classified with vitamin D sufficiency, independent of the cut-off criteria, had lower baseline glycaemia, although the rate of change of this biomarker did not differ between the two vitamin D status groups.

The definition of vitamin D sufficiency or insufficiency remains controversial. Currently, there are no specific cut-points for pregnant women, and the same cut-points are used for adults. It is well-known that the thresholds for several biomarkers are rarely available for this period of life, and the case is not different for vitamin $\mathrm{D}$. Thus, more research is needed to establish the adequate cut-off point for this unique period in women's life. In the current study, we opted to use two different thresholds presented by the two governing bodies of vitamin D status: the ESPG and the IOM. This strategy allows comparability with other studies in the literature and provides a broader picture of the studied associations in place. Another aspect of studies conducted during pregnancy that can be misleading is related to the timing vitamin D was assessed during pregnancy. The conclusions may vary if studies consider only baseline vitamin $\mathrm{D}$, for example, first trimester, what should be a representation of how pre-conception period affects the parameters evaluated throughout pregnancy. On the other end, if data are available for several time points, this can provide a clearer picture of the trajectory and how this may influence a specific outcome. In general, the directions of the rate of change trajectories for the studied outcomes were similar, regardless of the $25(\mathrm{OH}) \mathrm{D}$ threshold used. Adiponectin was the exception. Pregnant women with sufficient vitamin D levels at baseline showed significantly higher levels of adiponectin when the ESPG criteria was used, while according to the IOM classification, they showed lower levels, but the results were not significant. The results regarding the timing of vitamin D assessment yield slight conflicting results for insulin, HOMA-IR and leptin. Again, the direction of the associations remained the 
same, but the statistical significance of the interaction changed depending on the timing and threshold used. An important finding of this study is that differing conclusions can be made depending on the vitamin D deficiency threshold used or the timing when vitamin D status is evaluated. This is of particular importance when considering the conflicting results in the scientific literature.

The longitudinal data with three time points are an important strength of this study. We did not identify other studies assessing these associations with longitudinal data in the scientific literature. Moreover, the robust statistical analysis of the present study, taking into account the correlations between repeated measures and considering all women had information on at least two time points, is an additional strength. The method used to measure plasma 25(OH)D concentrations was LC-MS/ MS, which is considered the 'gold standard' for this marker. Furthermore, we also evaluated dietary vitamin D intake and supplementation. However, limitations, such as losses to follow-up and the absence of information about sun exposure data, should be acknowledged. To assess whether the losses to follow-up biased our results, we examined whether those women who were lost to follow-up differed from those who remained in the study. This analysis shows no significant differences in those who were lost to follow-up, which suggests that losses to follow-up occurred randomly in this study. We also adjusted all models for the season of the year at the time of blood collection, which was used as a proxy for sun exposure, since these data were not available. In addition, we did not measure the expression of enzymes that are involved in the conversion of vitamin $\mathrm{D}$ and the vitamin $\mathrm{D}$ receptor in the placenta to support extra-renal synthesis of 1,25-dihydroxyvitamin $\mathrm{D}_{3}\left(1,25(\mathrm{OH})_{2} \mathrm{D}_{3}\right)$ during pregnancy ${ }^{(46)}$. This could influence the outcomes; however, the maternal kidneys are likely to be the major source of increased maternal serum $1,25(\mathrm{OH})_{2} \mathrm{D}_{3}$ during pregnancy ${ }^{(46)}$.

A high prevalence of vitamin D insufficiency according to the ESPG was previously reported in this cohort ${ }^{(47)}$, which is similar to results found for pregnant women in other studies using this threshold ${ }^{(48,49)}$. Schneuer et $_{\text {al }}{ }^{(48)}$ observed that $80 \cdot 4 \%$ of 5109 pregnant women from Australia had vitamin D insufficiency in the first trimester. Flood-Nichols et al. ${ }^{(49)}$ found that $70 \%$ of 235 American women had vitamin D insufficiency in early pregnancy, while $59.0 \%$ of 190 Brazilian pregnant women presented vitamin D insufficiency ${ }^{(50)}$. We identified a low intake of vitamin $D$ during pregnancy $(3.4 \mu \mathrm{g} / \mathrm{d})$ in the present study by considering either the recommendation of the ESPG of $37 \cdot 5-50$ $\mu \mathrm{g} / \mathrm{d}$ or the Brazilian recommendations $(15 \mu \mathrm{g} / \mathrm{d})^{(51)}$. We also observed that none of the women used vitamin D supplements, since this is not part of public pre-natal care. In Brazil, only supplementation with $\mathrm{Fe}(40 \mathrm{mg})$ and folic acid $(400 \mathrm{mcg})$ are mandatory for pregnant women ${ }^{(52)}$. Despite low vitamin D dietary intake, we have previously reported a longitudinal increase in $25(\mathrm{OH}) \mathrm{D}$ levels throughout pregnancy in this cohort of women ${ }^{(47)}$. In addition, the level of increase in $25(\mathrm{OH}) \mathrm{D}$ concentrations depended on seasonal variation. Pregnant women who started their pregnancy during the winter, spring or autumn seasons had a significant longitudinal increase in $25(\mathrm{OH}) \mathrm{D}$ concentrations, while women who began pregnancy during the summer season showed no significant changes in $25(\mathrm{OH}) \mathrm{D}$ concentrations throughout pregnancy ${ }^{(47)}$.

In the current cohort, pregnant women with vitamin D insufficiency according to the ESPG had higher glycaemia in the first trimester compared to women with vitamin D sufficiency. This result corroborates with findings from an earlier crosssectional study with 155 Iranian pregnant women. That study showed a significant inverse association between first-trimester 25(OH)D concentrations and fasting glucose ( $r$ 0.238; $P=0.003)^{(53)}$. On another cross-sectional study, Casey et al. ${ }^{(54)}$ evaluated the association between vitamin $\mathrm{D}$ and glycaemia markers at the third gestation trimester and found no significant association with fasting glucose or HOMA-IR. These results are in line with the present findings regarding the third trimester. It seems that the relationship between vitamin $\mathrm{D}$ and glucose concentrations may be mediated by the role of vitamin $\mathrm{D}$ on insulin action.

Due to increased maternal adiposity and placental production, increased insulin resistance is expected to occur during pregnancy from the 18th gestational week until the third trimester $^{(55)}$. Peripheral insulin sensitivity decreases in the third trimester, and the hepatic glucose production increases compared to the beginning of pregnancy ${ }^{(56)}$. Vitamin D appears to play a role in insulin sensitivity, stimulating the expression of the insulin receptors and improving glycaemic metabolism ${ }^{(57-59)}$. Thus, glucose would be better absorbed by the cells, and glycaemia would be at lower levels.

The longitudinal analyses from the present study show that pregnant women with vitamin D sufficiency at baseline had sharper increases in insulin concentration compared to those with vitamin $\mathrm{D}$ insufficiency according to both thresholds used. The greater increase in insulin in the group with vitamin D adequacy was not followed by significant longitudinal increases in glycaemia or HOMA-IR during pregnancy. The active metabolite of vitamin $\mathrm{D}\left(1,25(\mathrm{OH})_{2} \mathrm{D}_{3}\right)$ has been shown to be involved in insulin secretion by the pancreas and glucose homoeostasis $^{(14)}$. In addition, pancreatic $\beta$-cells are known to have vitamin $\mathrm{D}$ receptors and an insulin gene promoter that is stimulated by $1,25(\mathrm{OH})_{2} \mathrm{D}_{3}$, thus indicating a direct association between vitamin $\mathrm{D}$ and insulin ${ }^{(60)}$. This mechanism could explain the greater insulin increase among women with vitamin D adequacy compared to those with vitamin D inadequacy in our sample. This result reinforces a small study performed with adults that found that subjects with vitamin D deficiency $(<50 \mathrm{nmol} / \mathrm{ml})$ secrete less insulin than subjects with adequacy status ${ }^{(61)}$.

A recent experimental study investigated the metabolic effects of adiponectin on maternal glucose and lipid metabolism by comparing pregnant rats with and without adiponectin deficiency ${ }^{(62,63)}$. The authors observed that adiponectin stimulated the $\beta$-cell proliferation and impaired the islet mass without differences in insulin sensitivity effects in comparison to the deficient group ${ }^{(4,62,63)}$. This finding allows suggesting another mechanism on insulin besides the well-established insulinsensitising property of this adipokine ${ }^{(62,63)}$. In humans, pregnant women present this phenomenon of $\beta$-cell proliferation without increase in islet mass, but this particular study was limited because it was conducted in women who died during 
pregnancy ${ }^{(64)}$. However, it is possible that adiponectin also exerts an effect on human cell proliferation ${ }^{(62)}$. Vitamin D could stimulate the adiponectin secretion, which in turn stimulates $\beta$-cell proliferation, increasing insulin secretion. This explanation would support our results of greater increases in adiponectin and insulin in pregnant women with vitamin D adequacy status during pregnancy.

We found an association between vitamin D status and the rate of change in adiponectin during pregnancy. In the present study, pregnant women with adequate levels of $25(\mathrm{OH}) \mathrm{D}$ in the first trimester showed a sharper increase in adiponectin concentration throughout pregnancy when compared to women with inadequate levels of vitamin $\mathrm{D}$. In addition, $1,25(\mathrm{OH})_{2} \mathrm{D}$ is known to regulate the RAAS in a negative feedback loop by binding with a transcription factor necessary for the expression of renin ${ }^{(65)}$. Inhibition of RAAS results in increased levels of adiponectin and improved insulin sensitivity, which exerts influence on glycaemia $^{(20)}$. This mechanism of action can explain our result of higher increase in adiponectin among pregnant women with adequate $25(\mathrm{OH}) \mathrm{D}$ levels compared to those with inadequate levels.

Previous studies found direct associations between vitamin D and adiponectin independent of BMI in both young and adult populations ${ }^{(66-68)}$, but no studies were found with pregnant women.

No differences were observed in mean adiponectin and leptin concentrations between pregnant women with vitamin D adequacy and inadequacy at each gestational trimester, that is, cross-sectional analysis. Similarly, a case-control study conducted by McManus et al. ${ }^{(69)}$ also found no correlation between $25(\mathrm{OH}) \mathrm{D}$ and adipokine concentrations during the third trimester in both healthy pregnant women and pregnant women with GDM.

A meta-analysis conducted in 2016 showed that vitamin D supplementation increased the serum leptin concentrations, although a meta-analysis using cross-sectional studies with nonpregnant subjects found inverse associations between $25(\mathrm{OH}) \mathrm{D}$ and leptin levels (Fisher's $Z=-0.93 ; 95 \% \mathrm{CI}-0.95,-0 \cdot 91)^{(31)}$. In the present cohort, it was observed that pregnant women with vitamin D sufficiency showed a less pronounced increase in leptin until the second trimester and a higher decrease until the end of gestation, although this did not reach significance. Similarly, Walsh et al. ${ }^{(70)}$ evaluated the correlation between $25(\mathrm{OH}) \mathrm{D}$ and leptin levels at early pregnancy and 28 weeks of gestation and found a negative association that was not significant.

\section{Conclusion}

Pregnant Brazilian women with vitamin D adequacy $(25(\mathrm{OH}) \mathrm{D}$ $\geq 75 \mathrm{nmol} / \mathrm{l}$ ) at the first trimester had a higher rate of increase in adiponectin and insulin concentrations throughout pregnancy compared to women with vitamin D inadequacy $(25(\mathrm{OH}) \mathrm{D}$ $<75 \mathrm{nmol} / \mathrm{l})$. These results indicate that vitamin $\mathrm{D}$ status at the beginning of gestation may influence the changes in adiponectin and insulin during pregnancy. Although these women had higher values of insulin, there were no higher glycaemia values, showing that there was an adequate metabolic response. This result reinforces the importance of monitoring the vitamin D status of pregnant women in the first trimester of pregnancy to achieve a favourable metabolic profile for reducing the risk of undesired pregnancy outcomes. Given the scarcity of studies, there is a need for research involving pregnant women to evaluate this relationship and to provide further evidence on this topic.

\section{Acknowledgements}

The authors are grateful to all participants of the cohort study, to the Municipal Health Centre Heitor Beltrão for giving us the space and allow the completion of data collection; to the Quest Diagnostics Nichols Institute laboratory (San Juan Capistrano, CA, USA) for performing the analyses of vitamin D. In addition, to the National Council for Scientific and Technological Development (CNPq in the Portuguese acronym; grant no. 471196/2010-0) and the Carlos Chagas Filho Foundation for Research Support of Rio de Janeiro State (FAPERJ in the Portuguese acronym, grant no. E-26/111.400/2010, E_14/2010) for the financial support. FAPERJ and CNPq had no role in the design, analysis or writing of this article.

C. B., P. G. C., G. K. formulated the research question, designed the study and developed the protocol. C. B. and P. G. C. conducted the statistical analysis, and N. H. A.-S. provided support for statistical analysis. E. G. d. B., A. B. F.-S., A. C. C. F., J. L., A. R. A. A., M. F. H. and R. M. assisted with the literature searches and with the writing of the manuscript. All authors substantially have contributed to and have approved the final version of this manuscript.

The authors declare that there are no conflicts of interest.

\section{Supplementary material}

For supplementary material/s referred to in this article, please visit https://doi.org/10.1017/S0007114518003057

\section{References}

1. Donazar-Ezcurra M, López-Del Burgo C \& Bes-Rastrollo M (2017) Primary prevention of gestational diabetes mellitus through nutritional factors: a systematic review. BMC Pregnancy Childbirth 17, 30.

2. Holick MF, Binkley NC, Bischoff-Ferrari HA, et al. (2011) Evaluation, treatment, and prevention of vitamin D deficiency: an Endocrine Society clinical practice guideline. J Clin Endocrinol Metab 96, 1911-1930.

3. Wei SQ, Qi HP, Luo ZC, et al. (2013) Maternal vitamin D status and adverse pregnancy outcomes: a systematic review and meta-analysis. J Matern Fetal Neonatal Med 26, 889-899.

4. Amegah AK, Klevor MK \& Wagner CL (2017) Maternal vitamin D insufficiency and risk of adverse pregnancy and birth outcomes: a systematic review and meta-analysis of longitudinal studies. PLOS ONE 12, e0173605.

5. Lau SL, Gunton JE, Athayde NP, et al. (2011) Serum 25hydroxyvitamin D and glycated haemoglobin levels in women with gestational diabetes mellitus. Med J Aust 194, 334-337.

6. Loy SL, Lek N, Yap F, et al. (2015) Association of maternal vitamin D status with glucose tolerance and caesarean section in a multi-ethnic Asian cohort: the growing up in Singapore towards healthy outcomes study. PLOS ONE 10, e0142239. 
7. Bener A, Al-Hamaq AO \& Saleh NM (2013) Association between vitamin $\mathrm{D}$ insufficiency and adverse pregnancy outcome: global comparisons. Int $J$ Womens Health 5 , 523-531.

8. World Health Organization (2013) Diagnostic Criteria and Classification of Hyperglycaemia First Detected in Pregnancy. Geneva: WHO.

9. Dinca M, Serban MC, Sahebkar A, et al. (2016) Does vitamin D supplementation alter plasma adipokines concentrations? A systematic review and meta-analysis of randomized controlled trials. Pharmacol Res 107, 360-371.

10. Karras SN, Polyzos SA, Newton DA, et al. (2018) Adiponectin and vitamin D-binding protein are independently associated at birth in both mothers and neonates. Endocrine 59, 164-174.

11. Rosen ED \& Spiegelman BM (2006) Adipocytes as regulators of energy balance and glucose homeostasis. Nature $\mathbf{4 4 4}$, $847-853$.

12. Lara-Castro C, Fu Y, Chung BH, et al. (2007) Adiponectin and the metabolic syndrome: mechanisms mediating risk for metabolic and cardiovascular disease. Curr Opin Lipidol 18, 263-270.

13. Rühl R \& Landrier JF (2016) Dietary regulation of adiponectin by direct and indirect lipid activators of nuclear hormone receptors. Mol Nutr Food Res 60, 175-184.

14. Sung CC, Liao MT, Lu KC, et al. (2012) Role of vitamin D in insulin resistance. J Biomed Biotechnol 2012, 634195.

15. Xu J, Zhao YH, Chen YP, et al. (2014) Maternal circulating concentrations of tumor necrosis factor-alpha, leptin, and adiponectin in gestational diabetes mellitus: a systematic review and meta-analysis. Scientific WorldJournal 201, 926932.

16. Retnakaran A \& Retnakaran R (2012) Adiponectin in pregnancy: implications for health and disease. Curr Med Chem 19, 5444-5450.

17. Ianniello F, Quagliozzi L, Caruso A, et al. (2013) Low adiponectin in overweight/obese women: association with diabetes during pregnancy. Eur Rev Med Pharmacol Sci 17, 3197-3205.

18. Mazaki-Tovi S, Romero R, Kusanovic JP, et al. (2008) Adiponectin multimers in maternal plasma.J Matern Fetal Neonatal Med 21, 796-815.

19. Nien JK, Mazaki-Tovi S, Romero R, et al. (2007) Plasma adiponectin concentrations in non-pregnant, normal and overweight pregnant women. J Perinat Med 35, 522-531.

20. Vaidya A, Forman JP, Underwood PC, et al. (2011) The influence of body mass index and renin-angiotensinaldosterone system activity on the relationship between 25-hydroxyvitamin D and adiponectin in Caucasian men. Eur J Endocrinol 164, 995-1002.

21. Tomaschitz A, Pilz S, Ritz E, et al. (2010) Independent association between 1,25-dihydroxyvitamin D, 25-hydroxyvitamin $\mathrm{D}$ and the renin-angiotensin system: the Ludwigshafen Risk and Cardiovascular Health (LURIC) study. Clin Chim Acta $\mathbf{4 1 1}$, 1354-1360.

22. Forman JP, Williams JS \& Fisher ND (2010) Plasma 25hydroxyvitamin $\mathrm{D}$ and regulation of the renin-angiotensin system in humans. Hypertension 55, 1283-1288.

23. Pala HG, Ozalp Y, Yener AS, et al. (2015) Adiponectin levels in gestational diabetes mellitus and in pregnant women without glucose intolerance. Adv Clin Exp Med 24, 85-92.

24. Mohammadi T \& Paknahad Z (2017) Adiponectin concentration in gestational diabetic women: a case-control study. Clin Nutr Res 6, 267-276.

25. Li ZY, Wang P \& Miao CY (2011) Adipokines in inflammation, insulin resistance and cardiovascular disease. Clin Exp Pharmacol Physiol 38, 888-896.
26. Song Y, Gao J, Qu Y, et al. (2016) Serum levels of leptin, adiponectin and resistin in relation to clinical characteristics in normal pregnancy and preeclampsia. Clin Chim Acta $\mathbf{4 5 8}$, 133-137.

27. Fatima SS, Alam F, Chaudhry B, et al. (2017) Elevated levels of chemerin, leptin, and interleukin-18 in gestational diabetes mellitus. J Matern Fetal Neonatal Med 30, 1023-1028.

28. Menendez C, Lage M, Peino R, et al. (2001) Retinoic acid and vitamin $\mathrm{D}$ (3) powerfully inhibit in vitro leptin secretion by human adipose tissue. J Endocrinol 170, 425-431.

29. Maetani M, Maskarinec G, Franke AA, et al. (2009) Association of leptin, 25-hydroxyvitamin $\mathrm{D}$, and parathyroid hormone in women. Nutr Cancer 61, 225-231.

30. Karonova T, Belyaeva O, Jude EB, et al. (2018) Serum $25(\mathrm{OH}) \mathrm{D}$ and adipokines levels in people with abdominal obesity. J Steroid Biochem Mol Biol 175, 170-176.

31. Hajimohammadi M, Shab-Bidar S \& Neyestani TR (2017) Vitamin D and serum leptin: a systematic review and metaanalysis of observational studies and randomized controlled trials. Eur J Clin Nutr 71, 1144-1153.

32. Considine RV, Sinha MK, Heiman ML, et al. (1996) Serum immunoreactive-leptin concentrations in normal-weight and obese humans. N Engl J Med 334, 292-295.

33. Fatima SS, Farooq S, Tauni MA, et al. (2015) Effect of raised body fat on vitamin D, leptin and bone mass. J Pak Med Assoc 65, 1315-1319.

34. Dinca M, Serban MC, Sahebkar A, et al. (2016) Does vitamin D supplementation alter plasma adipokines concentrations? A systematic review and meta-analysis of randomized controlled trials. Pharmacol Res 107, 360-371.

35. Mousa A, Abell SK, Shorakae S, et al. (2017) Relationship between vitamin $\mathrm{D}$ and gestational diabetes in overweight or obese pregnant women may be mediated by adiponectin. $\mathrm{Mol}$ Nutr Food Res 61, 18905-18909.

36. Pratumvinit B, Wongkrajang P, Wataganara T, et al. (2015) Maternal vitamin D status and its related factors in pregnant women in Bangkok, Thailand. PLOS ONE 10, e0131126.

37. Institute of Medicine (USA) (2011) Committee to Review Dietary Reference Intakes for Vitamin D and Calcium. In Dietary Reference Intakes for Calcium and Vitamin D, p. 8 [AC Ross, CL Taylor, AL Yaktine and HB Del Valle, editors]. Washington, DC: National Academies Press.

38. Matthews DR, Hosker JP, Rudenski AS, et al. (1985) Homeostasis model assessment: insulin resistance and beta-cell function from fasting plasma glucose and insulin concentrations in man. Diabetologia 28, 412-419.

39. Gordon CC, Chumlea WC \& Roche AF (1988) Stature, Recumbent Length, and Weight. Anthropometric Standardization Reference Manual. Champaign, IL: Human Kinetics Books.

40. Brazilian Institute of Geography and Statistics (2011) National Household Budget Survey. Nutritional Composition Table of Food Consumed in Brazil. Rio de Janeiro: Brazilian Institute of Geography and Statistics.

41. Sichieri R \& Everhart J (1998) Validity of a Brazilian food frequency questionnaire against dietary recalls and estimated energy intake. Nutr Res 18, 1649-1659.

42. Singer JD \& Willett JB (2003) Applied Longitudinal Data Analysis: Modeling Change and Event Occurrence. New York: Oxford University Press.

43. Twisk JW (2013) Applied Longitudinal Data Analysis for Epidemiology: A Practical Guide. Cambridge: Cambridge University Press.

44. Greenland S (1983) Tests for interaction in epidemiologic studies: a review and a study of power. Stat Med 2, 243-251.

45. Team RS (2015) RStudio: Integrated Development for $R$. Boston, MA: R Studio Inc. 
46. Liu NQ \& Hewison M (2012) Vitamin D, the placenta and pregnancy. Arch Biochem Biophys 523, 37-47.

47. Figueiredo AC, Cocate PG, Adegboye A, et al. (2018) Changes in plasma concentrations of 25-hydroxyvitamin D and 1,25dihydroxyvitamin D during pregnancy: a Brazilian cohort. Eur J Nutr 57, 1059-1072.

48. Schneuer FJ, Roberts CL, Guilbert C, et al. (2014) Effects of maternal serum 25-hydroxyvitamin D concentrations in the first trimester on subsequent pregnancy outcomes in an Australian population. Am J Clin Nutr 99, 287-295.

49. Flood-Nichols SK, Tinnemore D, Huang RR, et al. (2015) Vitamin D deficiency in early pregnancy. PLOS ONE 10, e0123763.

50. Pereira-Santos M, Queiroz Carvalho G, David Couto R, et al. (2018) Vitamin D deficiency and associated factors among pregnant women of a sunny city in Northeast of Brazil. Clin Nutr ESPEN 23, 240-244.

51. Maeda SS, Borba VZC, Camargo MBR, et al. (2014) Recommendations of the Brazilian Society of Endocrinology and Metabology (SBEM) for the diagnosis and treatment of hypovitaminosis D. Arq Bras Endocrinol Metab 58, 411-433.

52. BRAZIL (2013) National Program of Supplementation of Iron: Manual of General Conduct, p. 24. Ministry of Health, Secretariat of Health Care, Department of Basic Attention. Brasília, GO, Brazil: Ministry of Health.

53. Jafarzadeh L, Motamedi A, Behradmanesh M, et al. (2015) A comparison of serum levels of 25-hydroxy vitamin D in pregnant women at risk for gestational diabetes mellitus and women without risk factors. Mater Sociomed 27, 318-322.

54. Casey C, McGinty A, Holmes VA, et al. (2018) Maternal vitamin $\mathrm{D}$ and neonatal anthropometrics and markers of neonatal glycaemia: Belfast Hyperglycemia and Adverse Pregnancy Outcome (HAPO) study. Br J Nutr 120, 74-80.

55. Catalano P (2002) The diabetogenic state of maternal metabolism in pregnancy. NeoReviews 3, e165-e172.

56. Catalano PM, Tyzbir ED, Wolfe RR, et al. (1993) Carbohydrate metabolism during pregnancy in control subjects and women with gestational diabetes. Am J Physiol 264, E60-E67.

57. Alvarez JA \& Ashraf A (2010) Role of vitamin D in insulin secretion and insulin sensitivity for glucose homeostasis. Int $J$ Endocrinol 2010, 351385.

58. Tai K, Need AG, Horowitz M, et al. (2008) Vitamin D, glucose, insulin, and insulin sensitivity. Nutrition 24, 279-285.

59. Arnold DL, Enquobahrie DA, Qiu C, et al. (2015) Early pregnancy maternal vitamin $\mathrm{D}$ concentrations and risk of gestational diabetes mellitus. Paediatr Perinat Epidemiol 29, 200-210.

60. Altieri B, Grant WB, Casa SD, et al. (2017) Vitamin D and pancreas: the role of sunshine vitamin in the pathogenesis of diabetes mellitus and pancreatic cancer. Crit Rev Food Sci Nutr 57, 3472-3488.

61. Gedik O \& Akalin S (1986) Effects of vitamin D deficiency and repletion on insulin and glucagon secretion in man. Diabetologia 29, 142-145.

62. Retnakaran $\mathrm{R}$ (2017) Adiponectin and $\beta$-cell adaptation in pregnancy. Diabetes 66, 1121-1122.

63. Qiao L, Wattez JS, Lee S, et al. (2017) Adiponectin deficiency impairs maternal metabolic adaptation to pregnancy in mice. Diabetes 66, 1126-1135.

64. Butler AE, Cao-Minh L, Galasso R, et al. (2010) Adaptive changes in pancreatic beta cell fractional area and beta cell turnover in human pregnancy. Diabetologia $\mathbf{5 3}$, 2167-2176.

65. Yuan W, Pan W, Kong J, et al. (2007) 1,25-Dihydroxy vitamin $D_{3}$ suppresses renin gene transcription by blocking the activity of the cyclic AMP response element in the renin gene promoter. J Biol Chem 282, 29821-29830.

66. Gannagé-Yared MH, Chedid R, Khalife S, et al. (2009) Vitamin D in relation to metabolic risk factors, insulin sensitivity and adiponectin in a young Middle-Eastern population. Eur J Endocrinol 160, 965-971.

67. Nimitphong H, Chanprasertyothin S, Jongjaroenprasert W, et al. (2009) The association between vitamin D status and circulating adiponectin independent of adiposity in subjects with abnormal glucose tolerance. Endocrine 36, 205-210

68. Vaidya A, Williams JS \& Forman JP (2012) The independent association between 25-hydroxyvitamin D and adiponectin and its relation with BMI in two large cohorts: the NHS and the HPFS. Obesity (Silver Spring) 20, 186-191.

69. McManus R, Summers K, de Vrijer B, et al. (2014) Maternal, umbilical arterial and umbilical venous 25-hydroxyvitamin $\mathrm{D}$ and adipocytokine concentrations in pregnancies with and without gestational diabetes. Clin Endocrinol (Oxf) 80, 635-641.

70. Walsh JM, McGowan CA, Kilbane M, et al. (2013) The relationship between maternal and fetal vitamin $\mathrm{D}$, insulin resistance, and fetal growth. Reprod Sci $\mathbf{2 0}$, 536-541. 